\title{
The Electromagnetic Pollution of Wireless Electronic Equipment in Areas with High Human Accumulation
}

\author{
Antonios P Skountzos ${ }^{1}$, Dimitrios Nikolopoulos ${ }^{1 *}$, Ermioni Petraki ${ }^{1}$, Sofia Kottou ${ }^{2}$ and Panayotis H Yannakopoulos ${ }^{1}$ \\ ${ }^{1}$ Department of Electronic Computer Systems Engineering, Technological Education Institute of Piraeus, Petrou Ralli and Thivon 250, GR-12244, Aigaleo, Greece \\ ${ }^{2}$ University of Athens, Medical School, Department of Medical Physics, Mikras Asias 75, GR-11527 Athens, Greece
}

\begin{abstract}
Health concerns have been raised, especially following the enormous increase in the use of wireless mobile telephony (GSM, 3G and 4G) throughout the world. A similar situation exists regarding other digital wireless systems, such as data communication networks, Bluetooth, Wi-Fi, DECT phones and CB's which emit in various regions of the spectrum giving rise to cumulative radiation exposure. These concerns have induced a large body of research as mobile devices use electromagnetic waves in the microwave range.

In the present work, we have measured the EMF of various emitting devices at different frequencies as well as the contribution of wireless emitting ones in various areas of special interest such as Universities, hospitals, airports. The peaking measurement was at the entrance of the airport $(300 \mathrm{mV} / \mathrm{m})$ and the minimum $(7 \mathrm{mV} / \mathrm{m})$ in a "neutral University location" with the least human accumulation in comparison with the other studied places. The other studied emitting devices showed a logarithmic decrease, which is significant up to $50 \mathrm{~cm}$ away from the base station.
\end{abstract}

Keywords: Communication networks; Electromagnetic radiation; Mobile phones

\section{Introduction}

We are all now living in a "soup" of electromagnetic radiation, irradiated by mobile phones, satellites, broadcast antennas, aviation radar, TVs, computers, wireless internet, wireless LANs in working areas, [1] one billion times stronger than the natural fields in which living cells have developed over the last 3.8 billion years. So far only a few, faint warnings have been raised, mainly by people who are so sensitised to the electromagnetic radiation emitted by mobile devices and $\mathrm{Wi}-\mathrm{Fi}$, that they become ill in its presence. The World Health Organisation (WHO) estimates that $3 \%$ of the population are "electro-sensitive". A 2007 assessment published by the European Commission Scientific Committee on Emerging and Newly Identified Health Risks (SCENIHR) concluded that the three lines of evidence, viz. animal, in vitro, and epidemiological studies, indicate that "exposure to RF fields is unlikely to lead to an increase in humans" [2-4]. Scientists, doctors and some European governments are adding their voices to the growing alarm that the universal use of mobile devices may herald the start of a medical catastrophe for the future.

Mobile phone radiation and health concerns have been raised, especially following the enormous increase in the use of wireless mobile telephony throughout the world (In 2011, there were approximately 6 billion users compared to 2 billion users in 2005, worldwide). This is because mobile phones use electromagnetic waves in the microwave range-frequencies from $1 \mathrm{GHz}$ up to $30 \mathrm{GHz}$. These concerns have induced a large body of research both epidemiological and experimental, in animals as well as in humans.

A microwave is a type of energy in the form of electromagnetic wave, like radio waves or light waves, that travels with the speed of light $\left(3^{\star} 10^{8}\right.$ $\mathrm{m} / \mathrm{s}$ ). These waves are used in radars and other communication systems (to relay long distance telephone signals, TV programs, and computer information across the earth or to a satellite in space). Microwaves are also familiar in cooking, as a heating machine (approximately 2.5 $\mathrm{GHz}$ ). When frequencies at this range are absorbed, they result in atomic motion (heat) in the water, fat and sugar molecules of the food. Microwaves are reflected by metals, and they are not absorbed by most plastic, glasses and ceramics.

Prior to 1996, all cell phones were analogue devices that operated in the lower cellular frequency band than that of digital systems, which were introduced in 1997. The electromagnetic energy given off by cell phones is a type of non-ionizing radiation. Cell phones are portable radio devices that transmit and receive signals from a network of fixed, low-power, base stations. The transmitting power of a cell phone varies, depending on the type of the network and the distance from the base station. The power generally increases as you move farther away from the nearest base station. There is no evidence that the RF electromagnetic energy from cell phones and other such devices can break chemical bonds. So, it is unlikely to damage the body's genetic material.

Mobile phones have low-power transmitters and most of them have two signal strengths $0.6 \mathrm{~W}$ and $3 \mathrm{~W}$ with a maximum signal power of $5 \mathrm{~W}$ (for comparison, most $\mathrm{CB}$ radios transmit at 4 Watts). The base stations are also transmitting at low power. The power of the widely used microwave oven is from $0.5 \mathrm{KW}$ to $1.1 \mathrm{KW}$.

It is useful to compare the radiation of mobile telephones to that of microwave ovens, as mobile phones may operate in an environment that can be roughly modeled as a cavity, (i.e. cars, small rooms with reinforced concrete, outposts). It seems that mobile phones emit negligible radiation compared to the microwave ovens but a simple calculation presents exactly the opposite. If someone uses a mobile phone daily for one hour, the annual power is calculated as follows: 1 $\mathrm{h} /$ day $\times 365$ days/year $\times 3 \mathrm{~W}=1,095 \mathrm{Wh} /$ year.

*Corresponding author: Dimitrios Nikolopoulos, Department of Electronic Computer Systems Engineering, Technological Education Institute of Piraeus, Petrou Ralli and Thivon 250, GR-12244, Aigaleo, Greece, Tel: 0030-6977-208318 E-mail: dniko@teipir.gr

Received November 07, 2014; Accepted December 01, 2014; Published December 07, 2014

Citation: Skountzos AP, Nikolopoulos D, Petraki E, Kottou S, Yannakopoulos PH (2014) The Electromagnetic Pollution of Wireless Electronic Equipment in Areas with High Human Accumulation. J Civil Environ Eng 4: 163. doi:10.4172/2165784X.1000163

Copyright: @ 2014 Skountzos AP, et al. This is an open-access article distributed under the terms of the Creative Commons Attribution License, which permits unrestricted use, distribution, and reproduction in any medium, provided the original author and source are credited. 
Biological effects of electromagnetic fields at mobile phone frequencies have been subject to public debate. While the initial interest was on direct effects causing health problems or diseases, in more recent times the focus has changed to effects that reflect impairments of wellbeing, such as headaches, earaches, slow down brain speed, blurring of vision, short-term memory loss, numbing, burning sensations as well as loss of sleep. So far, the only known mechanism that mobile telephone radiation has had an effect on living tissue is heating [5].

The rise in temperature on the surface of the brain caused by radio waves is $0.3^{\circ} \mathrm{C}$ at the most. This magnitude temperature rise has no biological significance. The temperature of the brain normally fluctuates by about one degree, and only after an increase of $5^{\circ} \mathrm{C}$, cells may be damaged [6].

Investigations since 1994 by different scientists working on different fields have shown the following (Most of the experiments have been carried out on rats) [7].

Low-level (0.6 mW/g Specific Absorption Rate SAR) radiofrequency radiation exposure at $2450 \mathrm{MHz}$ results in memory deficiency. (Today the level of safety of a cellular telephone is estimated in SAR-level of radiation (emission) in watts of radiated energy on one $\mathrm{kg}$ of brain $(\mathrm{W} / \mathrm{kg})$ ). The memory deficiency was observed as an inability of the rats to find their way around a familiar area [8]. Virtually all operators of portable cellular phones subject themselves to such exposure and energy absorption while using the phone. Furthermore, the memory deficiency persisted for five days or more after the exposure ended.

During and after radiation exposure to low level pulsed radiofrequency radiation at power densities from 0.5 to $1.5 \mathrm{~mW} / \mathrm{cm}^{2}$, ten times lower than the typical exposure from a portable cellular telephone, the tested animals exhibited EEGs that show complex functional changes. The modifications to EEG are a result of the exposure to 2450 $\mathrm{MHz}$ pulsed radiation at $3 \mathrm{~mW} / \mathrm{cm}^{2}$. The EEG appears to return to normal about 20 minutes after cessation of exposure. Also, as it was tested in the laboratories, radiation changed the brain cell membranes in the rats, and the effects are so severe that it could affect humans, too [7].

Humans, exposed to low-levels of pulsed RF radiation at less than $1.0 \mu \mathrm{W} / \mathrm{cm}^{2}$, exhibit altered EEG signals $[4,7,9]$. This level is about 10,000 times lower than the radiation level to which users of portable cellular telephones are exposed. That is, after the last exposure has ended the EEG modifications in one's brain will continue to affect memory and motor skills for about a week, so every action that occurs within that individual's life during that next week will be affected by the EEG modifications resulting from the portable cellular telephone call.

Weak modulated radiofrequency radiation results in major physiological changes. These weak exposures, less than that which would result in temperature increases of $0.1^{\circ} \mathrm{C}$, have also been observed to produce chemical and behavioural changes [7]. The greatest effect on the organism of humans is caused by analogue standards of cellular communication such as NMT450i and AMPS. It is connected with the large power of both base stations and transmitters of telephones.

The modern digital standards, such as GSM1800 and CDMA have less effect on the organism of humans. According to the data of German scientists who have tested three standards of cellular communication NMT-450, GSM 900, GSM 1800 and 231 cardio stimulators of various manufacturers proved that more than $30 \%$ of the cardio stimulators are effected by telephones operating in standards NMT-450 and GSM 900. The influence of telephones standard GSM 1800 on cardio stimulators

was not revealed. The measurement of radiation near antennas of cellular communication was not carried out but it is possible to tell with confidence that the radiation power of the base station is from 6 up to $10 \mathrm{~W}$ but for a handset it is from $0.05 \mathrm{~W}$ up to $0.6 \mathrm{~W}$ [2,9-11].

\section{Measuring System}

The measuring system we used is a reliable and functional solution for measurements of the Electromagnetic Field (EMF). The block diagram is shown in Figure 1.

The relation between the LEDs and the field intensity is given in Table 1 where $\mathrm{P}_{\text {in }}(\mathrm{dBm})$ is the input Power, $\mathrm{E}(\mathrm{V} / \mathrm{m})$ the electric field intensity, $\mathrm{H}(\mu \mathrm{A} / \mathrm{m})$ the magnetic field intensity and $\mathrm{S}\left(\mu \mathrm{W} / \mathrm{m}^{2}\right)$ the power density $(\mathrm{S}=\mathrm{ExH})$. At the minimum of our scale, $-70 \mathrm{dBm}, \mathrm{E}=4.7$ $\mathrm{mV} / \mathrm{m}$ and at the maximum, $-5 \mathrm{dBm}, \mathrm{E}=8.3 \mathrm{~V} / \mathrm{m}$.

The electric field has an exponential increase. The first LED (D1) will be switched on at the intensity of $\approx 5 \mathrm{mV} / \mathrm{m}$. Each LED in the scale represents a value in $\mathrm{V} / \mathrm{m}$ increased by the factor 2.3 . If we use as unit $\mathrm{W} / \mathrm{m}^{2}$ the values are increasing faster (the rate is $(2.3)^{2}$, i.e. roughly 5.3). In order to detect the angular distribution of the electromagnetic intensity of microwaves, we need a circuit which will not only will be in position to process signals of frequencies up to $3 \mathrm{GHz}$, but also to dispose a bandwidth capable to detect with reliability fields with both small and high intensities.

Typical field intensities we could measure were in the range of our counter and therefore we did not need any preamplifier and we maintained the circuit simple enough. In the above region the IC provides a voltage between $0.55 \mathrm{~V}$ and $1.7 \mathrm{~V}$, where the lower value corresponds to $-70 \mathrm{dBm}$ and the highest to $-5 \mathrm{dBm}$. These voltage levels can drive the output without the need of any additional amplifying circuit.

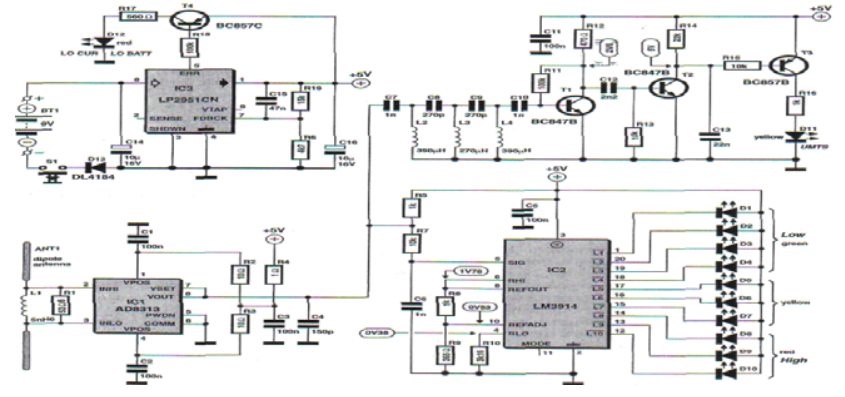

Figure 1: Block diagram of the measuring system.

\begin{tabular}{|l|c|c|c|c|c|}
\hline LED & LED Colour & $\mathbf{P}_{\text {in }}(\mathbf{d b m})$ & $\mathbf{E}(\mathbf{V} / \mathbf{m})$ & $\mathbf{H}(\boldsymbol{\mu} \mathbf{A} / \mathbf{m})$ & $\mathbf{S}\left(\boldsymbol{\mu} \mathbf{W} / \mathbf{m}^{2}\right)$ \\
\hline D1 & Green & -70 & 0.0047 & 12 & 0.056 \\
\hline D2 & Green & -62.8 & 0.011 & 28 & 0.293 \\
\hline D3 & Green & -55.6 & 0.025 & 60 & 1.5 \\
\hline D4 & Green & -48.3 & 0.057 & 145 & 8.3 \\
\hline D5 & Orange & -41.1 & 0.127 & 340 & 43 \\
\hline D6 & Orange & -33.9 & 0.300 & 780 & 230 \\
\hline D7 & Orange & -26.7 & 0.680 & 1.8 & 1.2 \\
\hline D8 & Red & -19.4 & 1.6 & 4 & 6.4 \\
\hline D9 & Red & -12.2 & 3.6 & 9.5 & 34 \\
\hline D10 & Red & -5 & 8.3 & 21.7 & 180 \\
\hline
\end{tabular}


Citation: Skountzos AP, Nikolopoulos D, Petraki E, Kottou S, Yannakopoulos PH (2014) The Electromagnetic Pollution of Wireless Electronic Equipment in Areas with High Human Accumulation. J Civil Environ Eng 4: 163. doi:10.4172/2165-784X.1000163
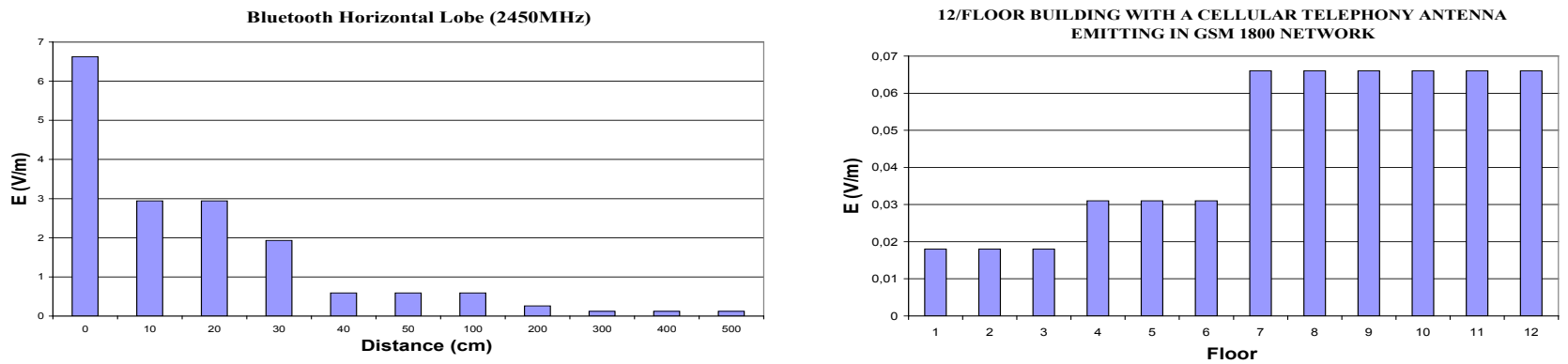

Figure 2: Vertical Electric Field Intensity vs distance (Bluetooth (@2450 MHz) and Antenna (@1800 MHz)).

\begin{tabular}{|c|c|c|c|c|c|}
\hline $\mathbf{f}(\mathbf{G H z})$ & Response (dB) & $\mathbf{f}(\mathbf{G H z})$ & Response (dB) & $\mathbf{f}(\mathbf{G H z})$ & Response (dB) \\
\hline 0.9 & -16.2 & 1.5 & -2.9 & 2.1 & -0.8 \\
\hline 1 & -14.2 & 1.6 & -2.0 & 2.2 & -1.6 \\
\hline 1.1 & -11.9 & 1.7 & -0.1 & 2.3 & -3.0 \\
\hline 1.2 & -8.4 & 1.8 & 1.5 & 2.4 & -4.5 \\
\hline 1.3 & -7.2 & 1.9 & 0.9 & 2.5 & -6.2 \\
\hline 1.4 & -3.3 & $\mathbf{2 . 0}$ & $\mathbf{0 . 0}$ & & \\
\hline
\end{tabular}

Table 2: Frequency response of the measuring system.

\begin{tabular}{|c|c|c|c|c|c|}
\hline \multicolumn{5}{|c|}{ E (V/m) } \\
\hline DIODE & \multicolumn{5}{|c|}{ Frequency (MHz) } \\
\hline & $\mathbf{9 0 0}$ & $\mathbf{1 8 0 0}$ & $\mathbf{1 9 0 0}$ & $\mathbf{2 4 0 0}$ & $\mathbf{2 4 5 0}$ \\
\hline D1 & 0.038 & 0.005 & 0.005 & 0.010 & 0.010 \\
\hline D2 & 0.090 & 0.011 & 0.012 & 0.023 & 0.025 \\
\hline D3 & 0.194 & 0.025 & 0.027 & 0.050 & 0.055 \\
\hline D4 & 0.419 & 0.054 & 0.058 & 0.109 & 0.119 \\
\hline D5 & 0.903 & 0.117 & 0.126 & 0.235 & 0.257 \\
\hline D6 & 2.066 & 0.269 & 0.288 & 0.537 & 0.589 \\
\hline D7 & 6.779 & 0.883 & 0.946 & 1.763 & 1.933 \\
\hline D8 & 10.330 & 1.346 & 1.442 & 2.686 & 2.945 \\
\hline D9 & 23.243 & 3.029 & 3.245 & 6.043 & 6.626 \\
\hline D10 & 52.943 & 6.899 & 7.393 & 13.766 & 15.094 \\
\hline
\end{tabular}

Table 3: Electromagnetic Field Intensity at various frequencies.

LM3914 is a monolithic integrated circuit that senses analog voltage levels and drives 10 LEDs, providing a linear analog display. A single pin changes the display from a moving dot to a bar graph. Current drive to the LEDs is regulated and is programmable eliminating the need for resistors. This feature is one that allows the operation of the whole system from less than $3 \mathrm{~V}$. The output current is programmable in the region from $2 \mathrm{~mA}$ to $30 \mathrm{~mA}$.

In Table 2 the frequency response of the measuring equipment at main frequencies is given. The response is zero at the frequency of 2 GHz. This frequency is in the region of UMTS (1900-2200 MHz), and close to DECT (1880-1900 MHz) and WiFi (2400-2480 MHz) carrier frequencies [12].

The calibrated values for the main frequencies are given in Table 3 which is derived from Tables 1 and 2 indicating for each LED, the electric field intensity needed in order to be switched on. All values are calculated using the equation: $20 \log \mathrm{V}_{0} / \mathrm{V}_{\text {in }}$ with the data from Tables 1 and 2 (i.e. $\mathrm{L} 8$ is switched on at $\mathrm{E}=1.6 \mathrm{~V} / \mathrm{m}$ (Table 1) and the spectral response of e.g. $900 \mathrm{MHz}$ is $-16.2 \mathrm{~dB}$. From the previous equation we obtain the value of $10.33 \mathrm{~V} / \mathrm{m}$ ).

\begin{tabular}{|c|c|c|c|}
\hline $\begin{array}{c}\text { Distance } \\
(\mathrm{cm})\end{array}$ & $\begin{array}{c}\mathbf{E}(\mathbf{V} / \mathbf{m}) \\
\text { (Headset and base } \\
\text { Attached together) }\end{array}$ & $\begin{array}{c}\mathbf{E}(\mathbf{V} / \mathbf{m}) \\
\text { for the headset }\end{array}$ & $\begin{array}{c}\mathbf{E}(\mathbf{V} / \mathbf{m}) \text { for the base } \\
\text { (Headset } 10 \mathrm{~m} \\
\text { away from the base) }\end{array}$ \\
\hline 0 & 7.393 & 7.393 & 7.393 \\
\hline 10 & 3.245 & 3.652 & 3.652 \\
\hline 20 & 3.245 & 1.775 & 3.652 \\
\hline 30 & 1.775 & 1.038 & 3.245 \\
\hline 50 & 1.775 & 1.038 & 1.775 \\
\hline 100 & 1.442 & 0.946 & 1.775 \\
\hline 200 & 1.038 & 0.946 & 1.038 \\
\hline 300 & 0.164 & 0.407 & 0.407 \\
\hline 400 & 0.031 & 0.164 & 0.164 \\
\hline 500 & 0.031 & 0.071 & 0.071 \\
\hline
\end{tabular}

Table 4: Horizontal Electric Field Intensity vs distance.

\begin{tabular}{|c|c|c|c|}
\hline Distance $(\mathrm{cm})$ & $\begin{array}{c}\mathbf{E}(\mathbf{V} / \mathbf{m}) \text { (Headset } \\
\text { and base } \\
\text { Attached together) }\end{array}$ & $\begin{array}{c}\mathbf{E}(\mathbf{V} / \mathbf{m}) \text { for the } \\
\text { headset }\end{array}$ & $\begin{array}{c}\mathbf{E}(\mathbf{V} / \mathbf{m}) \text { for the base } \\
\text { (Headset 10m away from } \\
\text { the base) }\end{array}$ \\
\hline 0 & 7.393 & 7.393 & 7.393 \\
\hline 10 & 1.775 & 3.652 & 1.775 \\
\hline 20 & 1.775 & 1.775 & 1.038 \\
\hline 30 & 1.038 & 1.775 & 0.946 \\
\hline 40 & 1.038 & 1.442 & 0.407 \\
\hline 50 & 0.946 & 1.038 & 0.288 \\
\hline
\end{tabular}

Table 5a: Vertical Electric Field Intensity vs distance.

\begin{tabular}{|c|c|c|c|c|}
\hline \multirow{2}{*}{ Distance (cm) } & \multicolumn{2}{|c|}{ GSM 1800 } & $\mathbf{E}(\mathbf{V} / \mathbf{m})$ & \multicolumn{2}{c|}{ 3G } & E(V/m) \\
\hline & Vertical Lobe & Horizontal Lobe & Vertical Lobe & Horizontal Lobe \\
\hline 0 & 6.899 & 6.899 & 1.07 & 1.07 \\
\hline 10 & 3.029 & 3.029 & 0.34 & 0.35 \\
\hline 20 & 1.968 & 1.968 & 0.14 & 0.13 \\
\hline 30 & 1.346 & 1.346 & 0.11 & 0.11 \\
\hline 40 & 0.883 & 0.991 & 0.11 & 0.11 \\
\hline 50 & $\mathbf{0 . 2 6 9}$ & $\mathbf{0 . 8 8 3}$ & 0.08 & 0.08 \\
\hline 100 & & 0.269 & & 0.06 \\
\hline 200 & & 0.117 & & 0.06 \\
\hline 300 & & 0.054 & & 0.03 \\
\hline 400 & & 0.051 & & 0.03 \\
\hline 500 & & 0.048 & & 0.03 \\
\hline
\end{tabular}

Table 5b: Vertical Electric Field Intensity vs distance, GSM 1800 and 3G.

At the dot mode, there is a small amount of overlap or "fade" (about $1 \mathrm{mV}$ ) between segments. This assures that at no time will all LEDs be "OFF", thus any ambiguous display is avoided. 
Citation: Skountzos AP, Nikolopoulos D, Petraki E, Kottou S, Yannakopoulos PH (2014) The Electromagnetic Pollution of Wireless Electronic Equipment in Areas with High Human Accumulation. J Civil Environ Eng 4: 163. doi:10.4172/2165-784X.1000163

Page 4 of 4

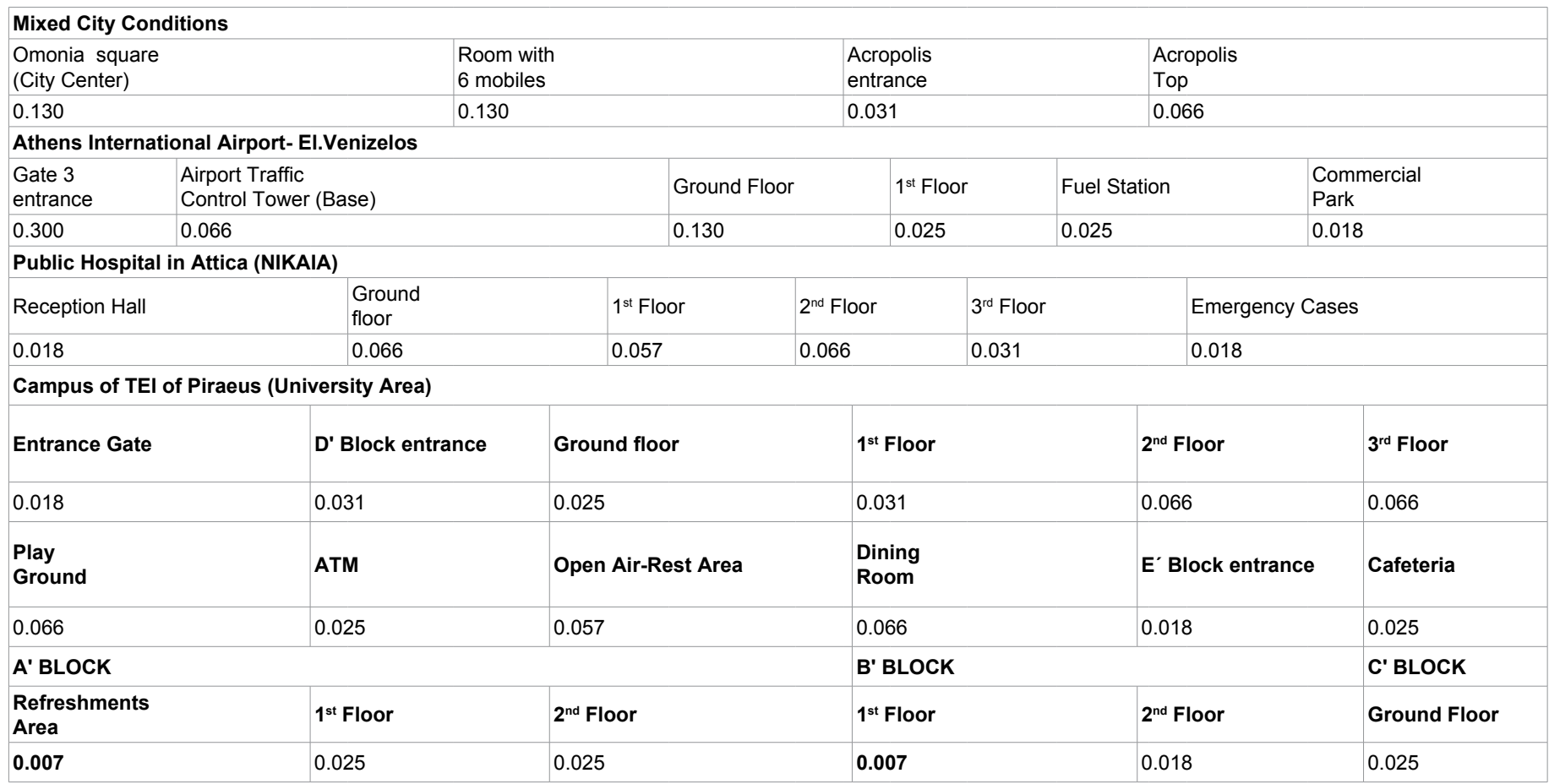

(All measurements are in $\mathrm{V} / \mathrm{m}$ (Electric Field Intensity))

Table 6: Measurements at places with high human accumulation.

\section{Measurements and Results \\ DECT phones (@1900 MHz)}

DECT phones, have significantly high signal level even when they are not in use, mainly if the base station is far away from the receiver. In Tables $4,5 \mathrm{a}$ and $5 \mathrm{~b}$, the electric field intensity of the horizontal and vertical radiation lobe for the base and the headset are given. The initial value decreases by $50 \% 10 \mathrm{~cm}$ away from the base station. All the following values are under 'talking' mode. The measurements were taken just above the set and $10 \mathrm{~m}$ away from the base for distances from 0-500 cm (Table 6 and Figure 2).

\section{Conclusion}

From our measurements it appears that, when several mobile phones, DECTs, Wi-Fi, Bluetooth, operate simultaneously in the same area high average signal values are measured in the area, which results in an aggravated environment. The measured values of EMF in the city center and a room with several emitting devices seems to be identical.

Only the measurements at the airport gate entrance were almost three times more. On the other side only the open rest air of the University campus showed a value half from the One in the city center. Also places being higher than the street level also seems to have a higher emf value.

For a DECT phone there is a significant difference between the base and the headset values for the benefit of the user-almost half [13]. Also there is a noticeable difference between the measurements for the horizontal and vertical lobe. Similar behaviour was measured also for the Bluetooth, GSM 1800, 3G and antennas.

Further measurements must be taken, to investigate all possible cases and risks. Concluding, it is necessary to mark that still for today it is impossible to tell exactly if the usage of a cellular phones is harmful or safe.

\section{Acknowledgement}

This research has been co-financed by the European Union (European Social Fund-ESF) and Greek national funds through the Operational Program "Education and Lifelong Learning" of the National Strategic Reference Framework (NSRF)Research Funding Program: THALES Investing in knowledge society through the European Social Fund.

\section{References}

1. Health Effects of Microwave Radiation (Western View) (2001) European Parliament STOA.

2. Scientific Committee on Emerging and Newly Identified Health Risks (2009) SCENIHR.

3. Moulder JE, Erdreich LS, Malyapa RS, Merritt J, Pickard WF (1999) Cell Phones and Cancer: What Is the Evidence for a Connection? Radiation Research 151: 513-531.

4. www.land-sbg.gv.at/celltower

5. James Protsman (2003) Cell Phone Radiation Slows Down Brain Speed.

6. Effects of mobile telephone radiation (2009) STUK.

7. The Associated Bioeletromagetics Technologists, 2004.

8. Lai H, Singh NP (1995) Acute low-intensity microwave exposure increases DNA single strand breaks in rat brain cells. Bioelectromagnetics 16: 207-210.

9. Cellular telephone and safety of health (2000) IXBT Labs.

10. Adey WR (1980) Frequency and Power Windowing in Tissue Interactions with Weak Electromagnetic Fields. Proceedings of the IEEE 68: 119-125.

11. Zracenje mobilnih telefona-najnovija lista, Ergonomija.

12. Elektor.

13. Distance and the Inverse Square Law, EMF WISE. 